\title{
Effect of tibial tray design on cement morphology in total knee arthroplasty
}

Ulf J Schlegel ${ }^{1 *}$, Klaus Püschel ${ }^{2}$, Michael M Morlock ${ }^{3}$ and Katrin Nagel ${ }^{3}$

\begin{abstract}
Background: Improvements to enforce primary fixation in cemented total knee arthroplasty have been suggested to be a key issue for long-term survival. In this context, it has been questioned whether specific implant design features influence bone cement morphology and hence primary interface strength. The purpose of this study was to investigate in vitro the influence of cement pockets on the tibial tray on cement penetration in the tibia.

Methods: Eight paired cadaveric, human tibiae were available for investigation. One side of a pair was implanted with a fixed bearing tibial tray (FB) featuring cement pockets on the undersurface, while in the other side, a mobile bearing platform (MB) without cement pockets was used. Specimens underwent computed tomography analysis of the cement morphology as well as BMD assessment.
\end{abstract}

Results: While bone cement layer between implant and bone surface was thicker in the FB group $(p=0.032)$, bone cement penetration was not influenced by implant design $(p=0.529)$.

Conclusions: The present study suggests that cement pockets do not alter or enforce bone cement penetration under the tibial tray in an in vitro scenario.

Keywords: Total knee arthroplasty, Cementing technique, Mobile bearing, Cement pockets, Bone cement penetration

\section{Background}

Cemented total knee arthroplasty (TKA) is widely accepted as the most effective treatment for end-stage osteoarthritis of the knee. Although favorable clinical results have been reported, aseptic loosening of the tibial component remains troublesome [1-3]. As the need for revision surgery in total knee arthroplasty increases steadily, there is growing interest to improve initial fixation [4]. Aseptic loosening can be attributed to continuous micromotion at the implant-cement or bone-cement interface [5]. There is increasing evidence that the interface strength of the cemented fixation at the time of surgery is a major factor determining the long-term performance of the implant [6,7]. However, there is little information regarding bone cement penetration characteristics with newer tray designs for alternative

\footnotetext{
* Correspondence: ulf.schlegel@gmx.net

${ }^{1}$ Center for Orthopedics and Trauma Surgery, Heidelberg University Hospital, Schlierbacher Landstr 200a, 69118 Heidelberg, Germany

Full list of author information is available at the end of the article
}

bearing philosophies such as mobile bearing platforms. There has been a higher prevalence of tibial failure with early component designs, which highlights the role of the implant itself in the loosening process [8]. Implants featuring a peripheral lip on the undersurface have been suggested to enforce cement penetration, but the presence is depending on the manufacturer and the design [9]. Another biomechanical study suggested likewise that surface preparation and type of metal substrate may influence the bonding of the tibial component to the cement [10]. Thus, it can be questioned if cement mantle morphology differs among tibial trays of different designs. Design features on the undersurface of the component could influence bone cement penetration and likewise morphology in the trabecular bone, which could alter initial fixation strength. Hence, the aim of this study was to evaluate and compare bone cement penetration patterns in the tibial cancellous bone between different tibial tray designs by computed tomography $(\mathrm{CT})$ scans and 3D imaging. 


\section{Methods}

The study was conducted using eight paired proximal, cadaveric tibiae. The specimens were conserved in a freezer at $-30^{\circ} \mathrm{C}$ and thawed overnight before experiments were carried out at room temperature $\left(22^{\circ} \mathrm{C}\right)$. The age of the donors was 82 years at median ranging from 71 to 87 . All tibiae underwent CT analysis for determination of BMD and to exclude specimens with osseous aberrations (Brilliance 40-channel, Philips Medical Systems, Haifa, Israel). BMD was assessed relating Hounsfield units in a rectangular volume of $4,000 \mathrm{~cm}^{3}$ in the tibial head to a calibration normal (Avizo 5.0, VSG, Burlington, MA, USA). Two different tibial components were investigated in the study: P.F.C. Sigma Ti Fixed Bearing (FB) and P.F. C. Sigma MBT Keeled (mobile bearing = MB). The FB trays are made of titanium, while the latter consists of a cobalt chromium alloy (DePuy Orthopaedics, Warsaw, IN, USA). Both trays are designed for cemented fixation. While the P.F.C. FB provides a peripheral lip with posterior cement pockets with undercuts on the undersurface, the P.F.C. MB provides a smaller peripheral and central lip without specific pockets and undercuts (Figure 1). To facilitate implantation and handling, a screw thread was cut into the FB trays. This was not possible in the MB trays due to the cone-shaped opening for the inlay. Therefore, the tip of the stem was cut off and replaced by a tip featuring an inside screw (Figure 2). The specimens were then prepared for implantation of the tibial trays (size 3) following the manufacturer's guidelines using a $0^{\circ}$ slope cutting block and corresponding punches (DePuy Orthopaedics, Warsaw, IN, USA). All surgeries were carried out by the first author. In the final preparation step, all bones were cleaned using a syringe lavage and $1,800 \mathrm{ml}$ saline solution. Pulsed lavage was not used as pilot measurements showed that the effect of pulsed lavage could overlay any other cementing effect. After careful drying, bone cement was vacuum mixed (60 s) and hand pressurized on the tibial surfaces after a waiting period of $120 \mathrm{~s}$ (Smartset HV $40 \mathrm{~g}$, DePuy Orthopaedics, Warsaw, IN, USA). The stem of the implant was left cementless (surface cementing technique). The components were impacted by ten mallet blows; a steel lid was applied after impaction to apply constant axial loading of $50 \mathrm{~N}$ until the cement was cured. The specimens were then again evaluated by CT scans for analysis of the cement morphology in detail. The median cement layer thickness extending from the undersurface of the implant to the bony surface was determined. Accordingly, the median bone cement penetration reaching from the osseous surface into the cancellous bone was analyzed. This was done using a previously established method with a 3D imaging software and a numerical computing package (Avizo 5.0, VSG, Burlington, MA, USA and MATLAB, The MathWorks Inc., Natick, MA, USA), as outlined in detail elsewhere [11]. Statistical analysis comparing cement layer thickness and penetration depth was performed by a paired $t$-test provided that the distribution of the data is parametric (GraphPad Software, Inc., La Jolla, CA, USA). BMD as a structural parameter was controlled for by the paired design and also compared between designs using one-way ANOVA. A type I error probability of $5 \%$ was used for all tests. Continuous data were described by mean and standard deviation or-where applicable-by median and range.

\section{Results}

BMD was similar for the two tray design groups (FB: $64 \mathrm{mg} / \mathrm{cm}^{3}, \mathrm{SD}=45 \mathrm{mg} / \mathrm{cm}^{3} ; \mathrm{MB}: 63 \mathrm{mg} / \mathrm{cm}^{3}, \mathrm{SD}=$ $37 \mathrm{mg} / \mathrm{cm}^{2} ; p=0.967$; Table 1 ). The mean bone cement

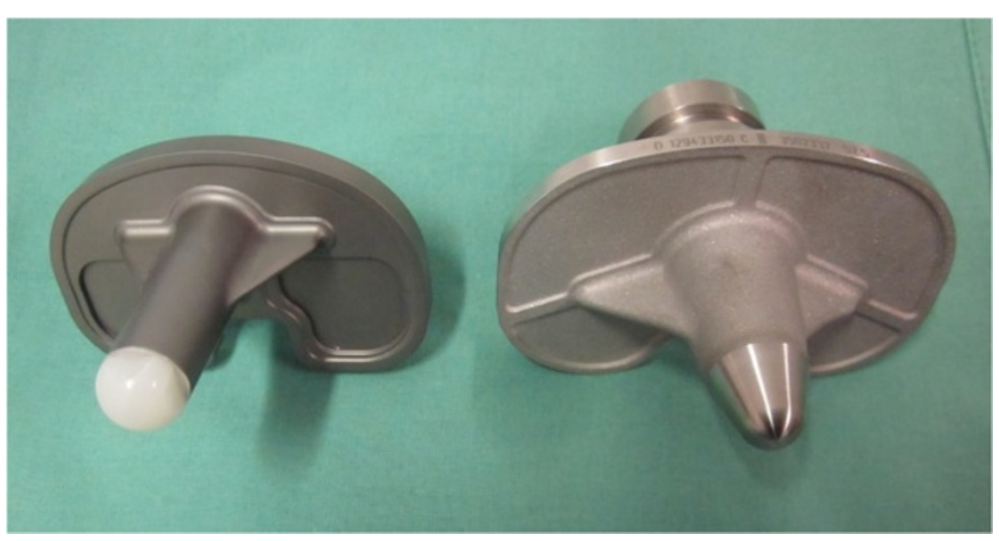

Figure 1 Undersurface of FB with posterior cement pockets (left) and MB (right). 


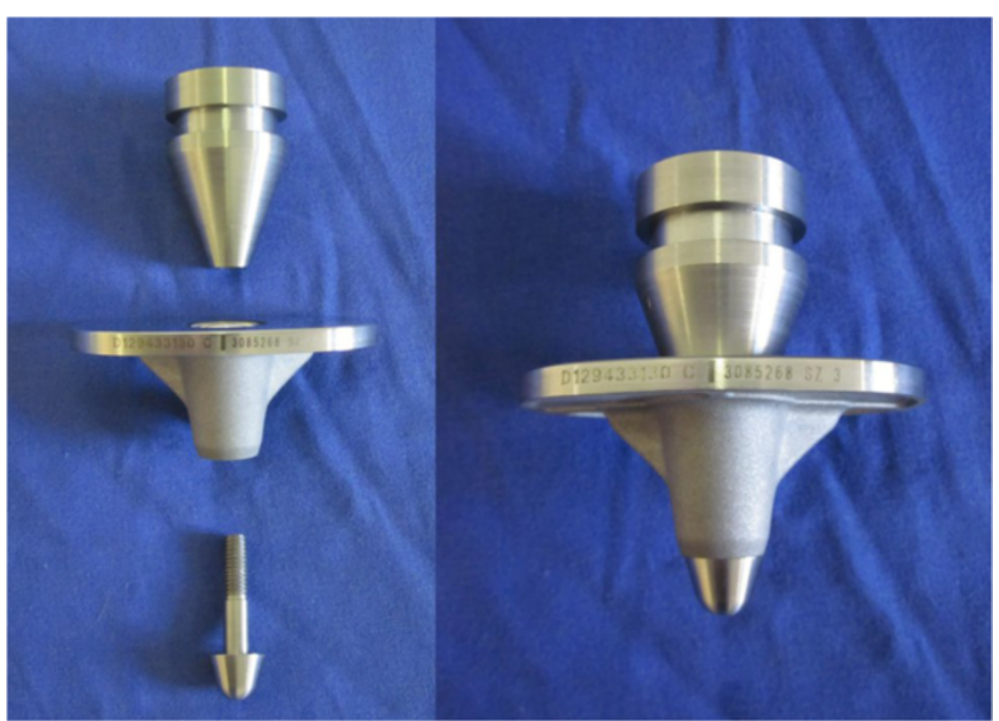

Figure 2 Modification for testing of MB trays: disassembled (left) and assembled (right).

penetration was also similar: $1.07 \mathrm{~mm}(\mathrm{SD}=0.23 \mathrm{~mm})$ for the $\mathrm{FB}$ and $1.16 \mathrm{~mm}(\mathrm{SD}=0.19 \mathrm{~mm})$ for the $\mathrm{MB}$ group ( $p=0.529$; Figure 3$)$. Cement layer thickness between the undersurface of the implant and the osseous surface was higher for the $\mathrm{FB}(2.32 \mathrm{~mm}, \mathrm{SD}=$ $0.22 \mathrm{~mm})$ than for the $\mathrm{MB}(1.47 \mathrm{~mm}, \mathrm{SD}=0.27 \mathrm{~mm}$, $p=0.032$ ). Examples for the cement mantle reconstructions generated from the CT data are shown in Figures 4 and 5.

\section{Discussion}

Differences in tibial component design and surgical technique influence the long-term performance of the implant regarding early aseptic loosening in TKA [12]; cementing techniques and choice of implant design still

Table 1 Specimen characteristics and results $(F=$ female, $\mathbf{M}=$ male)

\begin{tabular}{lcccccc}
\hline Specimen & Sex & Age & $\begin{array}{c}\text { Tray } \\
\text { type }\end{array}$ & $\begin{array}{c}\text { BMD } \\
\left(\mathbf{m g} / \mathbf{c m}^{3}\right)\end{array}$ & $\begin{array}{c}\text { Cement } \\
\text { layer }(\mathbf{m m})\end{array}$ & $\begin{array}{c}\text { Penetration } \\
(\mathbf{m m})\end{array}$ \\
\hline $1 \mathrm{R}$ & $\mathrm{M}$ & 71 & $\mathrm{MB}$ & 16 & 1.14 & 1.40 \\
$1 \mathrm{~L}$ & & & $\mathrm{FB}$ & 13 & 2.64 & 0.96 \\
$2 \mathrm{R}$ & $\mathrm{F}$ & 81 & $\mathrm{FB}$ & 55 & 2.25 & 1.42 \\
$2 \mathrm{~L}$ & & & $\mathrm{MB}$ & 62 & 1.65 & 1.23 \\
$3 \mathrm{R}$ & $\mathrm{F}$ & 87 & $\mathrm{MB}$ & 65 & 1.37 & 1.05 \\
$3 \mathrm{~L}$ & & & $\mathrm{FB}$ & 66 & 2.12 & 0.97 \\
$4 \mathrm{R}$ & $\mathrm{M}$ & 83 & $\mathrm{FB}$ & 122 & 2.26 & 0.93 \\
$4 \mathrm{~L}$ & & & $\mathrm{MB}$ & 106 & 1.73 & 0.97 \\
\hline
\end{tabular}

are controversial $[13,14]$. It has been shown that a peripheral lip improves bone cement penetration into the osseous surface [9]. The present study investigated in vitro whether cement pockets on the undersurface could likewise influence bone cement penetration characteristics. A cement pocket could possibly increase penetration by entrapment of bone cement in the undercutting area and directing it into the cancellous bone surface. However, the effect could not be observed in this in vitro scenario. Overall cement penetration was similar in the FB and $\mathrm{MB}$ group. The results from Vertullo and Davey on 177 consecutive TKA showed

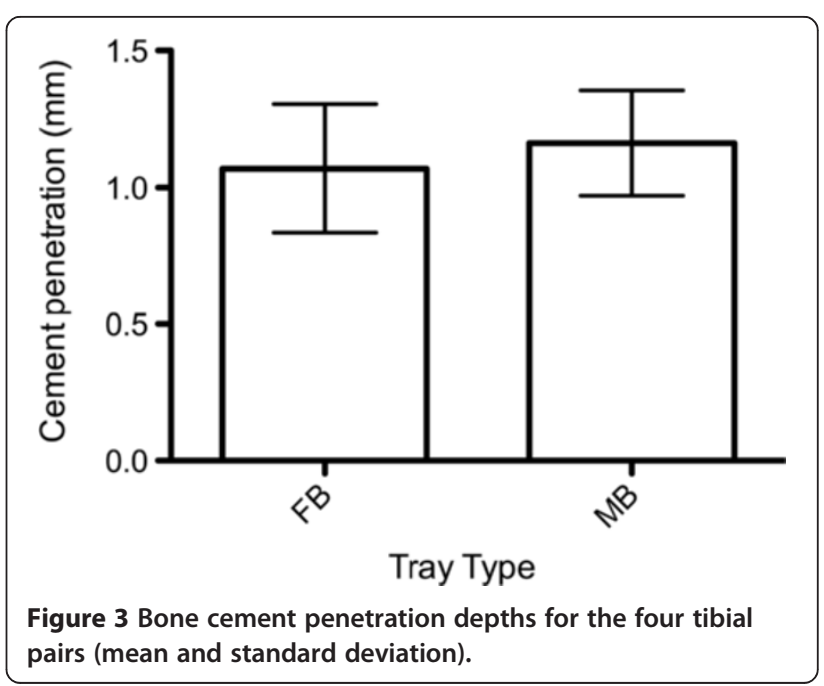




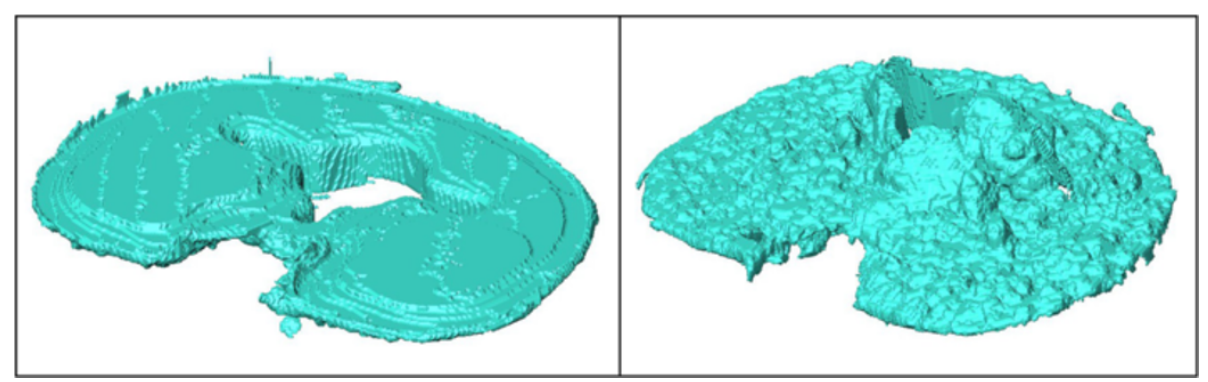

Figure 4 Examples of 3D reconstructions of P.F.C. Sigma ${ }^{\circledR}$ Ti Fixed Bearing bone cement mantles. Left: top view, right: undersurface.

twice as deep cement penetration in lipped baseplates compared to unlipped ones [9]. However, the data was derived from radiographs, which is questionable as the implants and the keels obscure some of the cemented area. In our experience, accuracy of discrimination between cement under the baseplate and real penetration is difficult and error-prone under those circumstances. Furthermore, the actual cement penetration depth into the bone could not be visualized by the cited study setup due to the interference of cement with flanges and stem and only the lateral part of the tray was studied. In our observation, the overall penetration depths were similar in both groups, as we could not observe a significant increase in cement penetration in the FB group. On the other hand, a cement pocket may enforce rotational stability. However, this issue was not investigated in the present study. Penetration depths in our setting ranged from 0.93 to $1.42 \mathrm{~mm}$ and match perfectly with the data retrieved in a preceding investigation [11]. A mean cement penetration of 3 to $4 \mathrm{~mm}$ has been suggested to be the optimum for implant fixation [15-17]. Comparing the values to our data indicates that former studies could not differentiate between cement layer under the tray and actual penetration. Hence, cement penetration has probably been reported as a combination of both components, which might explain the observed differences. Further studies on bone cement penetration should focus on the "real" penetration into cancellous bone, as presented here. The thickness of the cement layer extending from the undersurface of the implant to the osseous surface was higher in the FB group (mean $2.32 \mathrm{~mm}$ ) compared to the MB group (mean $1.47 \mathrm{~mm}$ ). This effect is most likely related to the cement pockets of the FB implant and suggests that cement layer thickness is mainly influenced by implant design. Whether a thicker cement mantle is beneficial or detrimental is unclear and needs further research.

The small sample size is a limitation of the study. However, since the effects were similarly observed for each pair, the small sample size should not have biased the results. The transfer of in vitro testing to in vivo conditions remains limited, which has to be kept in mind when interpreting the presented results.

\section{Conclusions}

In summary, the present study suggests that cement pockets with undercuts do not alter or enforce bone cement penetration under a tibial tray in an in vitro scenario.

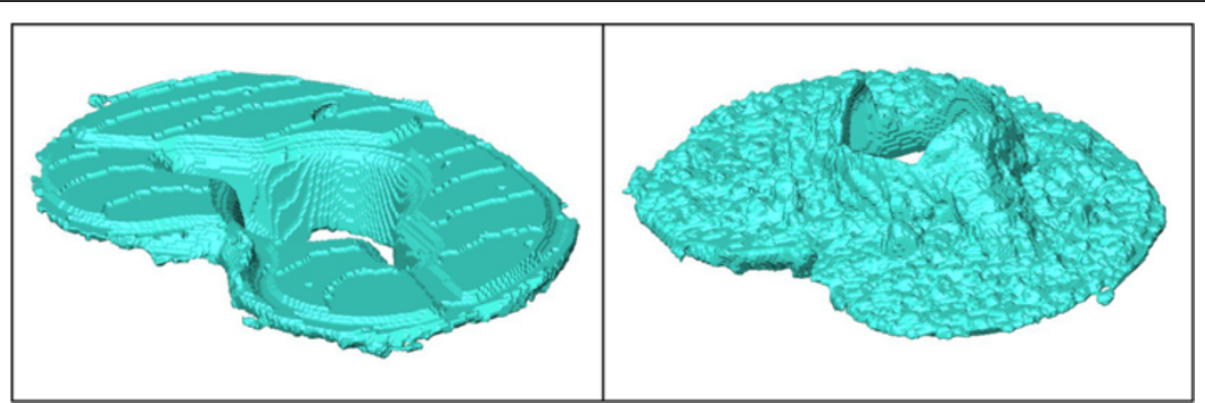

Figure 5 Examples of 3D reconstructions of P.F.C. Sigma ${ }^{\circledR}$ MBT Keeled bone cement mantles. Left: top view, right: undersurface. 


\section{Competing interests}

UJS is working as a consultant for DePuy Orthopaedics. For all other authors, no competing interests are declared.

\section{Authors' contributions}

UJS and KN carried out the surgery, CT, analysis, testing, and prepared the manuscript. KP participated in the anatomical preparation and drafted the manuscript. MMM conceived the mechanical testing, performed the statistical analysis, and prepared the manuscript. All authors read and approved the final manuscript.

\section{Acknowledgements}

Financial support for this study was received from DePuy Orthopaedics. Furthermore, we acknowledge financial support by Deutsche

Forschungsgemeinschaft and Ruprecht-Karls-Universität Heidelberg within the funding program Open Access Publishing.

\section{Author details}

'Center for Orthopedics and Trauma Surgery, Heidelberg University Hospital, Schlierbacher Landstr 200a, 69118 Heidelberg, Germany. ${ }^{2}$ Institute of Legal Medicine, University of Hamburg-Eppendorf, Butenfeld 34, 22529 Hamburg, Germany. ${ }^{3}$ Biomechanics Section, TUHH Hamburg University of Technology, Denickestr 15, 21073 Hamburg, Germany.

Received: 7 August 2014 Accepted: 18 November 2014

Published online: 29 November 2014

\section{References}

1. Buehler KO, Venn-Watson E, D'Lima DD, Colwell CW Jr: The press-fit condylar total knee system: 8- to 10-year results with a posterior cruciate-retaining design. J Arthroplasty 2000, 15:698-701.

2. Parsch D, Kruger M, Moser MT, Geiger F: Follow-up of 11-16 years after modular fixed-bearing TKA. Int Orthop 2009, 33:431-435.

3. Lachiewicz PF, Soileau ES: The rates of osteolysis and loosening associated with a modular posterior stabilized knee replacement. Results at five to fourteen years. J Bone Joint Surg Am 2004, 86-A:525-530.

4. Kurtz SM, Ong KL, Schmier J, Mowat F, Saleh K, Dybvik E, Karrholm J, Garellick G, Havelin LI, Furnes O, Malchau H, Lau E: Future clinical and economic impact of revision total hip and knee arthroplasty. J Bone Joint Surg Am 2007, 89(Suppl 3):144-151.

5. Jacobs JJ, Shanbhag A, Glant TT, Black J, Galante JO: Wear debris in total joint replacements. J Am Acad Orthop Surg 1994, 2:212-220.

6. Lombardi AV Jr, Berasi CC, Berend KR: Evolution of tibial fixation in total knee arthroplasty. J Arthroplasty 2007, 22:25-29.

7. Vanlommel J, Luyckx JP, Labey L, Innocenti B, De Corte R, Bellemans J: Cementing the tibial component in total knee arthroplasty: which technique is the best? J Arthroplasty 2011, 26(3):492-496.

8. Ducheyne P, Aernoudt E, De Meester P, Martens M, Mulier JC, Van Leeuwen $D$ : Factors governing the mechanical behavior of the implant-porous coating-trabecular bone interface. J Biomech 1978, 11:297-307.

9. Vertullo CJ, Davey JR: The effect of a tibial baseplate undersurface peripheral lip on cement penetration in total knee arthroplasty. J Arthroplasty 2001, 16:487-492.

10. Pittman GT, Peters $\mathrm{CL}$, Hines $\mathrm{JL}$, Bachus KN: Mechanical bond strength of the cement-tibial component interface in total knee arthroplasty. J Arthroplasty 2006, 21:883-888

11. Schlegel UJ, Siewe J, Delank KS, Eysel P, Puschel K, Morlock MM, de Uhlenbrock AG: Pulsed lavage improves fixation strength of cemented tibial components. Int Orthop 2011, 35:1165-1169.

12. Lachiewicz PF, Soileau ES: Fifteen-year survival and osteolysis associated with a modular posterior stabilized knee replacement. A concise follow-up of a previous report. J Bone Joint Surg Am 2009, 91:1419-1423.

13. Rossi R, Bruzzone M, Bonasia DE, Ferro A, Castoldi F: No early tibial tray loosening after surface cementing technique in mobile-bearing TKA. Knee Surg Sports Traumatol Arthrosc 2010, 18(10):1360-1365.

14. Cawley DT, Kelly N, McGarry JP, Shannon FJ: Cementing techniques for the tibial component in primary total knee replacement. Bone Joint J 2013, 95-B:295-300.

15. Walker PS, Soudry M, Ewald FC, MCVickar H: Control of cement penetration in total knee arthroplasty. Clin Orthop Relat Res 1984, 185:155-164.
16. Lutz MJ, Pincus PF, Whitehouse SL, Halliday BR: The effect of cement gun and cement syringe use on the tibial cement mantle in total knee arthroplasty. J Arthroplasty 2009, 24:461-467.

17. Kopec M, Milbrandt JC, Duellman T, Mangan D, Allan DG: Effect of hand packing versus cement gun pressurization on cement mantle in total knee arthroplasty. Can J Surg 2009, 52:490-494.

doi:10.1186/s13018-014-0123-2

Cite this article as: Schlegel et al: Effect of tibial tray design on cement morphology in total knee arthroplasty. Journal of Orthopaedic Surgery and Research 2014 9:123.

\section{Submit your next manuscript to BioMed Central and take full advantage of:}

- Convenient online submission

- Thorough peer review

- No space constraints or color figure charges

- Immediate publication on acceptance

- Inclusion in PubMed, CAS, Scopus and Google Scholar

- Research which is freely available for redistribution

Submit your manuscript at www.biomedcentral.com/submit
C Biomed Central 